\title{
ÍNDICE DE BASILÉIA NO BRASIL: BANCOS PÚBLICOS X PRIVADOS
}

\author{
THE BASEL INDEX IN BRAZIL: \\ PUBLIC X PRIVATE BANKS
}

\section{ÍNDICE DE BASILEA EN BRASIL: BANCOS PÚBLICOS X PRIVADOS}

\section{OTÁVIO RIBEIRO DE MEDEIROS*}

Graduado em Engenharia Mecânica pela PUC-RJ, Mestrado em Administração pelo Instituto Coppead (UFRJ), Mestrado em Economia pelo Birkbeck College (Universidade de Londres), Doutorado em Economia pela Universidade de Southampton - Reino Unido e professor titular da Universidade de Brasília - UnB

otavio@unb.br

\section{EMERSON JADER PANDINI**}

Graduado em Ciências Contábeis pela UnB.

valinor2211@yahoo.com.br

\section{RESUMO}

O artigo tem como objetivo verificar se o Índice de Basiléia dos bancos públicos e privados nacionais se comporta de modo diferente em função de o controle acionário dos bancos ser privado ou estatal. No intuito de elucidar essa questão, o trabalho utiliza como metodologia o teste estatístico não-paramétrico de Mann-Whitney. Por meio desse teste verificou-se se o Índice de Basiléia correspondente ao tipo de controle acionário dos bancos (público ou privado) seria um fator de diferenciação, isto é, se existe diferença significativa entre o valor médio do índice dos bancos públicos e dos privados no período compreendido entre os anos 2001 e 2006. Os resultados empíricos revelaram que não é possível rejeitar a hipótese de que o Índice de Basiléia médio de bancos públicos é equivalente àquele dos bancos privados. 
Palavras-chave: Índice da Basiléia. Teste de Mann-Whitney. Patrimônio de Referência. Patrimônio Líquido Exigível. Bancos Brasileiros.

\section{ABSTRACT}

This paper aims at verifying whether the Basel Index of national public and private banks behaves differently according to their shareholder control being private or state-owned. With the purpose of clarifying this question, our methodology utilizes the non-parametric statistical test of Mann-Whitney. By means of this method, we tested whether the Basel Index corresponding to the banks' shareholder control (public vs. private) would be a discrimination factor, i.e. if there exists a significant difference between the mean value of the Basel Index of public vis-à-vis private banks within the period from 2001 and 2006. The empirical results show that it is not possible to reject the hypothesis that the average Basel Index of public banks is equivalent to that of private banks.

Keywords: Basel Index. Mann-Whitney test. Reference Net Worth. Liable Net Worth. Brazilian Banks.

\section{RESUMEN}

El artículo tiene como objetivo verificar si el Índice de Basilea de los bancos públicos y privados nacionales se comprta de modo diferente en función del control accionario de los bancos ser privado o estatal. En el designio de dilucidar esa cuestión, el trabajo utiliza como metodología la prueba estadística en el paramétrico de Mann-Whitney. Por medio de esa prueba se verificó si el Índice de Basilea correspondiente al tipo de control accionario de los bancos (públicos o privados) sería un factor de diferenciación, esto es, si existe diferencia significativa entre el valor medio del índice de los bancos públicos y de los privados en el período comprendido entre los años 2001 y 2006. Los resultados empíricos revelaron que no es posible rechazar la hipótesis de que el Índice de Basilea medio de bancos públicos es equivalente a aquél de los bancos privados.

Palabras-Clave: Índice de la Basilea. Prueba de Mann-Whitney. Patrimonio de Referencia. Patrimonio Líquido Exigible. Bancos Brasileños.

\section{INTRODUÇÃO}

A diminuição da possibilidade de crise sistêmica no Sistema Financeiro Internacional é objeto de busca incessante dos bancos centrais, entidades supervisoras e reguladoras 
dos principais países cujos sistemas bancários se encontram em elevado grau de desenvolvimento. A constatação feita pelo Grupo dos Dez, de que a intensa concorrência entre os bancos teve como efeito colateral um perigoso encolhimento do seu capital, ensejou o estabelecimento, em 1988, do Acordo de Capital da Basiléia. Conforme descrito pelo Comitê da Basiléia sobre a Fiscalização Bancária (CBFB e BCBS, na sigla em inglês) (2001, p.13), "O capital é necessário para os bancos como uma margem de segurança contra perdas e fornece um incentivo para os proprietários de negócios administrarem-nos de forma prudente". O Grupo dos Dez é formado, na verdade, por 12 países: Bélgica, Canadá, França, Alemanha, Itália, Japão, Luxemburgo, Países Baixos, Suécia, Suíça, Reino Unido e Estados Unidos. O Comitê da Basiléia sobre Fiscalização Bancária, estabelecido pelos dirigentes dos bancos centrais dos países do Grupo dos Dez, em 1975, reúne autoridades de fiscalização bancária dos diversos países (CBFB, 2001, p.1). Dessa forma, a partir do advento do Acordo de 1988, os bancos internacionalmente ativos dos países do Grupo dos Dez ficaram obrigados a manter um determinado capital mínimo de uma cesta de ativos mensurada de acordo com sua suscetibilidade ao risco (CBFB, 2001, p.13).

No Brasil, os preceitos do Acordo foram regulamentados pelo CMN (Conselho Monetário Nacional) por meio da Resolução $n^{\circ} 2.099 / 94$, de 17 de agosto de 1994. Assim, o País passou a buscar maior aderência aos padrões internacionais dos sistemas bancários das principais economias do mundo, notadamente no que diz respeito à solvência e à liquidez. Desde então, a regulamentação vem sofrendo constantes atualizações, por conta, principalmente, da necessidade de adequar o sistema bancário brasileiro ao Novo Acordo de Capital da Basiléia, que entrou em vigor em 2004. Em essência, o Novo Acordo possui o mesmo objetivo do de 1988, sendo uma atualização mais complexa e incorporando novos conceitos à medida que se desenvolveu o setor bancário neste período.

No entanto, não se pode deixar de levar em consideração que a natureza do acionista controlador de uma instituição bancária traz sérias implicações quanto a decisões estratégicas, estilo de administração, comportamento perante risco, e accountability, entre outros aspectos. Assim, é de se esperar que bancos estatais tenham um comportamento diverso dos bancos privados em várias áreas. Há várias razões para que essa diferença ocorra. Por exemplo, há a influência política. Muitos bancos estatais têm seus dirigentes nomeados por razões político-partidárias e não por critérios profissionais. Em conseqüência, tais bancos podem vir a adotar critérios políticos para a concessão de crédito, que podem não ser compatíveis com a racionalidade econômica e a eficiência empresarial. Além disso, bancos estatais podem eventualmente estar a serviço de políticas populistas que venham, por exemplo, a inflar seu quadro de funcionários, em detrimento da eficiência econômico-financeira.

Há possivelmente também uma postura diferenciada entre bancos estatais e privados em relação ao risco. É possível que eventuais dirigentes não profissionais de bancos 
estatais induzam a instituição a uma maior exposição ao risco, concedendo créditos de risco elevado além do que seria razoável. O raciocínio por trás de tais atitudes está geralmente associado ao fato de que, em caso de falência, o dirigente espera que a instituição venha a ser socorrida pelo governo, principalmente no caso de bancos estaduais. Nas ultimas décadas, as falências, intervenções e liquidações de um grande número de bancos estatais estaduais comprovam a pertinência desses argumentos.

A motivação deste estudo deriva da percepção, aparentemente disseminada na sociedade, de que os bancos públicos não precisam preocupar-se em manter níveis de capital adequados para fazer frente aos riscos de seus ativos, pois, em situações de insolvência, haveria oportunas intervenções governamentais, na forma de capitalização, que evitariam a falência. A imprensa nacional registra abundantemente a ocorrência desses fatos no passado, não só em relação a bancos comerciais e de fomento estaduais, mas até mesmo de instituições federais, como o Banco do Brasil e a Caixa Econômica Federal. Por outro lado, os bancos privados, em princípio, não dispõem de socorro governamental. Portanto, devem equilibrar-se nas duas posições aparentemente antagônicas de maximizar o lucro e manter a solidez do capital com vistas a mitigar a possibilidade de crise gerada por insuficiência de capital.

O presente trabalho propõe-se a abordar o Índice de Capital, conhecido no Brasil por Índice de Basiléia, ou Quociente de Solvabilidade, e sua relação com o tipo de controle dos bancos. Dessa forma, o objetivo do presente trabalho consiste em testar empiricamente se, no Brasil, o Índice de Basiléia dos bancos públicos difere daquele dos bancos privados. Para atingir tal objetivo, será testada a seguinte hipótese:

H1: No Brasil, não há diferença estatisticamente significativa entre o Índice de Basiléia dos bancos públicos e o dos bancos privados.

Caso tal hipótese seja estatisticamente rejeitada, será possível afirmar que há evidências de que o referido Índice de Basiléia dos bancos brasileiros é afetado pelo tipo de controle acionário, isto é, se público ou privado.

\section{REFERENCIAL TEÓRICO}

\subsection{A crise sistêmica e o Índice de Basiléia}

Como foi discutido no tópico anterior, os bancos privados devem equilibrar-se entre a maximização do lucro e a capacidade de absorver perdas, mitigando o risco de quebra (default). Todavia, tais instituições tendem a reduzir seus capitais ociosos objetivando o lucro. Em um ambiente altamente competitivo como o em que atuam os bancos, aqueles "[...] sujeitos a menores requerimentos de capital poderiam oferecer mais crédito a taxas diferenciadas aos clientes" (Maia, 1996, apud Ono, 2002, p.6). A conseqüência imediata de referida ausência de requerimento de capital mínimo cria uma inequívoca vantagem competitiva a estes bancos. 


\section{repec}

Com os bancos cada vez menos capitalizados, a possibilidade de crise sistêmica provocada pela quebra de um desses entes do sistema financeiro não poderia mais ser ignorada, tampouco subestimada. É nesse contexto que o Acordo de Basiléia se insere, ao determinar requisitos mínimos de capital nos sistemas bancários ao mesmo tempo em que busca assegurar maior eqüidade competitiva entre os bancos, conforme observa Ono (2002, p.6).

Pelo Acordo, os bancos dos países signatários ficam obrigados a manter um capital mínimo relativo de $8 \%$ em relação ao seu total de ativos. Faz-se mister observar, todavia, que os ativos devem ser ponderados pela sua suscetibilidade ao risco de crédito. Exemplificando: se um banco possui determinado ativo mensurado no valor de $\$ 75$ e o risco inerente a esse ativo é da ordem de 100\% (risco pleno), o banco deve manter \$6 em seu Patrimônio Líquido, isto é: $\$ 75 \times 100 \% \times 8 \%=\$ 6$. Caso o ativo possua risco menor, digamos de $50 \%$, a necessidade de capital reduz-se para $\$ 3$, pois $\$ 75 \times 50 \% \times 8 \%=\$ 3$. Logo, o risco é fator preponderante para determinar a adequação de capital do banco aos parâmetros impostos pelo Acordo de Basiléia.

\subsection{O Acordo de Basiléia e o Brasil}

Em decorrência de o Brasil ser signatário do Acordo de Basiléia, os bancos do Sistema Financeiro Nacional, tanto públicos como privados, são obrigados a seguir os parâmetros estabelecidos pelo Acordo. As entidades responsáveis pela normatização do assunto, adequando-o à realidade brasileira, são o Banco Central (BACEN) e o CMN (Conselho Monetário Nacional), que, por meio da Resolução CMN n².099, de 17 de agosto de 1994, instituiu o conceito de Patrimônio Líquido Ajustado - que posteriormente viria a se transformar em Patrimônio Líquido Exigido - e o impôs aos bancos, em consonância com as diretrizes do Acordo. No caso brasileiro, a exigência de capital mínimo relativo é ainda mais rigorosa, atingindo $11 \%$ do total de ativos ponderados pelo grau de risco. Dessa forma, o BACEN restringiu ainda mais a alavancagem dos bancos, na medida em que impôs maior participação de capital próprio nas respectivas estruturas de capital daqueles.

Supõe-se que os bancos participantes do Sistema Financeiro Nacional, em sua absoluta maioria, estão em conformidade com o percentual mínimo de capital preconizado pelas autoridades supervisoras, pelo menos no tocante à amostra do presente trabalho, que abrange o período compreendido entre os anos de 2001 e 2006, de forma que o objeto de estudo não consiste em identificar Instituições Financeiras que estejam infringindo as Normas ou que demonstrem incapacidade, ainda que potencial, de atendê-las. Porém, cabe a seguinte indagação: supondo que os bancos privados devam ser mais competitivos no mercado, primando pela eficácia de gestão e maximização do lucro, estariam eles mais empenhados em manter o requerimento de capital estritamente no limite do que impõe a Norma, ou seja, de $11 \%$ ? Por outro lado, os bancos públicos podem, em tese, recorrer à ajuda governamental e, além disso, desempenham função social, com foco no desenvolvimento e na execução 


\section{repec}

de políticas públicas, entre outras atribuições que não visam estritamente ao lucro. Estariam essas instituições financeiras preocupadas com o requerimento de capital mínimo? Não se pode desconsiderar que os bancos públicos estão sujeitos a influências políticas de toda sorte, fato que em si mesmo é passível de prejudicar uma administração mais eficiente.

Para responder objetivamente às indagações acima, recorreu-se à estatística nãoparamétrica. Caso a hipótese não seja rejeitada, não haverá diferença estatisticamente significativa entre o Índice de Basiléia de um banco público e o de um banco privado. Em outras palavras, o analista ou usuário da informação que se basear apenas no Índice de Basiléia de determinada instituição não poderia inferir, com razoável grau de certeza, tratarse de instituição pública ou privada.

Espera-se que a hipótese nula seja rejeitada, isto é, que o Índice de Basiléia dos bancos privados se encontrará muito próximo do requerimento mínimo de $11 \%$, ao passo que o dos bancos públicos não tenderá a este limite. Em se rejeitando a hipótese nula, será constatada, por assim dizer, maior "folga" no índice dos bancos públicos.

\subsection{O Índice de Basiléia}

Objetivando uma melhor compreensão da informação de que trata o Índice de Basiléia, julgou-se necessário, preliminarmente, entender as duas variáveis de que aludido o índice trata. São elas: PLE (Patrimônio Líquido Exigido) e PR (Patrimônio de Referência). Antes, contudo, é imperativo esclarecer o principal conceito emanado do Acordo: o conceito de capital, o qual foi enunciado para dar vazão ao "[...] preceito de que a robustez do sistema está relacionada ao tamanho do capital das instituições, de modo a estabelecer uma relação entre o capital mínimo das instituições financeiras e as contas do ativo de tais instituições" (Toneto; Gremaud,1994 apud Ono, 2002, p.9). Ressalta-se que a necessidade mínima de capital é objeto principal do Acordo de Basiléia de 1988 e permanece no Novo Acordo, o qual passou a ser composto de três pilares:

Pilar 1: Discorre acerca da Necessidade Mínima de Capital

Pilar 2: Discorre acerca do Processo de Exame de Fiscalização

Pilar 3: Discorre acerca da Disciplina de Mercado

Assim, apresenta-se a seguir, de forma sucinta, alguns conceitos julgados básicos para o melhor entendimento do Índice de Basiléia, visto que o nosso estudo não abrange o Índice em si, mas a relação dele com o tipo de controle exercido em cada banco.

Segundo Silva (2005, p.21), o Brasil adequou-se às definições do Acordo de Basiléia por meio da Resolução CMN n² 2.837, de 2001, ao introduzir o conceito de Patrimônio de Referência (PR). O PR subdivide-se em dois níveis: I e II. Ainda segundo Silva, o Nível I do PR associa-se ao conceito tradicional de capital, correspondendo fundamentalmente ao patrimônio líquido, acrescido do saldo das contas de resultado credoras, e deduzido do saldo 
das contas de resultado devedoras, excluindo as reservas de reavaliação, as reservas para contingências e as reservas especiais de lucro relativas a dividendos obrigatórios não distribuídos e deduzidos os referentes a ações preferenciais cumulativas e ações preferenciais resgatáveis. Para Silva (2005), o Nível II do PR é uma inovação, na medida em que eleva ao status de capital regulamentar alguns instrumentos de dívida, sendo este nível constituído pelas reservas de reavaliação, reservas para contingências, reservas especiais de lucros relativas a dividendos obrigatórios não distribuídos, ações preferenciais cumulativas, ações preferenciais resgatáveis, dívidas subordinadas e instrumentos híbridos de capital e dívida. Para informações detalhadas acerca do PR, recomenda-se a leitura das Resoluções CMN n².837 e n².891, ambas de 2001.

\subsubsection{O Patrimônio Líquido Exigido (PLE)}

Como o próprio nome indica, o Patrimônio Líquido Exigido (PLE) refere-se à "[...] obrigatoriedade da manutenção de patrimônio líquido ajustado em valor compatível com o grau de risco das operações ativas das instituições financeiras e demais instituições autorizadas a funcionar pelo Banco Central [...]" (Silva, 2005, p. 19). Conforme expõe Silva (2005, p.18), o Ativo Ponderado pelo Risco inclui o ativo circulante e realizável a longo prazo, o ativo permanente e coobrigações multiplicados pelos respectivos fatores de risco de crédito, esse último associado à probabilidade de inadimplência.

Os diversos fatores de risco para cálculo do Ativo Ponderado pelo Risco (APR) são evidenciados na Tabela 1:

\section{Tabela 1 - Ponderações das categorias de ativos de acordo com o risco de crédito}

\begin{tabular}{l|l}
\hline \multicolumn{1}{c|}{ Ativo } & $\begin{array}{c}\text { Fator de risco para cálculo } \\
\text { do ativo ponderado }\end{array}$ \\
\hline $\begin{array}{l}\text { Reserva bancária, caixa, operações ativas de responsabilidade } \\
\text { ou com garantia do Tesouro Nacional e de depósitos no BACEN }\end{array}$ & $0 \%$ (risco nulo) \\
\hline $\begin{array}{l}\text { Depósitos bancários, aplicações em ouro e cheques enviados à } \\
\text { compensação }\end{array}$ & $20 \%$ (risco reduzido) \\
\hline $\begin{array}{l}\text { Operações ativas de responsabilidade ou com garantias de } \\
\text { outras instituições financeiras (CDI) }\end{array}$ & $50 \%$ (risco reduzido) \\
\hline $\begin{array}{l}\text { Operações ativas de responsabilidade ou com garantia } \\
\text { de Estados e Municípios, empréstimos e financiamentos, } \\
\text { aplicações em ações, moedas de privatização e permanente }\end{array}$ & $100 \%$ (risco normal) \\
\hline $\begin{array}{l}\text { Créditos tributários decorrentes de imposto de renda e } \\
\text { contribuição social }\end{array}$ & $300 \%$ \\
\hline
\end{tabular}

Fonte: Silva $(2005$, p.20) 
Note-se que o Comitê aborda a suscetibilidade dos ativos ao risco como forma de promover segurança e solidez no sistema financeiro. De forma a cumprir este intento, Ono (2002, p. 18) explica que "As instituições deverão adotar políticas na área de crédito que avaliem melhor o cliente e que associem garantias às operações. As garantias implícitas (especialmente as de governo) deverão ser melhor avaliadas, pois estão associadas às decisões políticas". Todavia, o autor adverte que gerenciar riscos não se resume à minimização destes, "[...] pois o controle da extensão e do volume dos vários tipq̨)de riscos, dentro de seus limites apropriados, é essencial para assegurar o bom funcionamento das atividades bancárias." (Ono, 2002, p. 18).

Após determinar o valor do Ativo Ponderado pelo Risco (APR), deve-se multiplicá-lo por um fator - denominado fator $\mathrm{F}$ - igual a 0,11 (onze centésimos). Além da ponderação do ativo, o PLE incorpora em seu bojo os riscos de crédito das operações de swap, em operações cambiais e com ouro e o risco de mercado de taxas de juros prefixadas. A regulamentação mais atual que versa sobre o PLE são a Resolução CMN n 2.891 e a Circular Bacen n³.064, ambas de 2001.

Assim, segundo Silva (2005, p.22) o PLE é composto da seguinte forma:

$P L E=F \times A P R+($ Swap + Cambial + Juros $) \downarrow^{*}$

onde Swap, Cambial e Juros referem-se aos riscos supra mencionados.

Uma vez apresentados, ainda que de forma introdutória, os conceitos de Patrimônio de Referência (PR) e Patrimônio Líquido Exigido (PLE), pode-se entender o conceito do Índice de Basiléia como sendo "[...] a relação entre o capital do banco e a exigência de patrimônio líquido para cobertura dos riscos envolvidos nas operações bancárias" (Ono, 2002, p. 51).

Dessa forma, conforme observa Silva (2005, p.24), a fórmula atual para calcular o Índice de Basiléia é:

$$
I B=\frac{P R \cdot 100}{\left\{A P R+\left[\frac{1}{F}(\text { Swap }+ \text { Cambial }+ \text { Juros })\right]\right\}}
$$

Onde o fator $\mathrm{F}$ é igual a 0,11 (onze centésimos), aplicado aos três tipos de Risco. A relação mínima exigida pelo BACEN, desde 1997, é de $11 \%$, o que significa dizer que a Instituição Financeira sujeita à Norma deve manter patrimônio líquido mínimo que possa atuar como "amortecedor" em caso de inadimplência ou perdas decorrentes de investimentos com graus de riscos mais acentuados.

\section{METODOLOGIA}

Para efetuar o presente estudo empírico, foram selecionados os 50 maiores bancos brasileiros, de acordo com seus Ativos Totais em junho de 2006. O período 


\section{repec}

de estudo é compreendido entre junho de 2001 a junho de 2006, considerando-se a periodicidade anual. Como somente 34 bancos permaneceram entre os 50 maiores nesse período, a amostra ficou reduzida a esses bancos. A Tabela 2 apresenta os valores obtidos para os índices em questão, para cada uma das instituições bancárias da amostra no período.

Para cada instituição, foi calculado o valor médio do índice no período de estudo como também os desvios-padrões dos índices para cada uma das instituições, bem como para os dois grupos em estudo, Bancos Públicos e Privados, que são apresentados na Tabela 3.

A classificação dos bancos da amostra deu-se da seguinte maneira, de acordo com o tipo de controle acionário:

- Bancos Públicos: Banco do Brasil (BB), Caixa Econômica Federal (CEF), Nossa Caixa, Banco do Estado do Rio Grande do Sul (Banrisul), Banco do Nordeste do Brasil (BNB), Banco da Amazônia (BASA), Banco do Estado do Espírito Santo (Banestes), Banco do Estado de Santa Catarina (BESC) e Banco de Brasília (BRB). 
Tabela 2 - Índice de Basiléia (\%) para as Instituições Bancárias da amostra - 2000 a 2006

\begin{tabular}{|c|c|c|c|c|c|c|c|c|c|}
\hline $\begin{array}{c}\text { Posição } \\
\text { em Jun } \\
06\end{array}$ & Instit & $\begin{array}{c}\text { Controle } \\
\text { Acionário }\end{array}$ & $\begin{array}{c}\text { Jun } \\
06\end{array}$ & $\begin{array}{c}\text { Jun } \\
05\end{array}$ & $\begin{array}{c}\text { Jun } \\
04\end{array}$ & $\begin{array}{c}\text { Jun } \\
03\end{array}$ & $\begin{array}{c}\text { Jun } \\
02\end{array}$ & $\begin{array}{c}\text { Jun } \\
01\end{array}$ & $\begin{array}{c}\text { Média } \\
2001 \text { a } \\
2006\end{array}$ \\
\hline 1 & BB & Público & 17,28 & 15,72 & 14,39 & 13,79 & 11,53 & 11,95 & 14,11 \\
\hline 2 & CEF & Público & 25,72 & 17,67 & 17,58 & 18,43 & 13,68 & 14,84 & 17,99 \\
\hline 3 & BRADESCO & Privado & 18,67 & 18,21 & 18,07 & 16,36 & 14,31 & 13,30 & 16,49 \\
\hline 4 & ITAU & Privado & 16,06 & 17,89 & 19,79 & 17,07 & 15,73 & 14,23 & 16,80 \\
\hline 5 & UNIBANCO & Privado & 15,01 & 16,12 & 16,73 & 16,72 & 13,42 & 14,40 & 15,40 \\
\hline 6 & SANTANDER BANESPA & Privado & 13,61 & 15,60 & 16,40 & 16,39 & 13,56 & 11,82 & 14,56 \\
\hline 7 & ABN AMRO & Privado & 14,42 & 17,45 & 18,41 & 14,64 & 14,95 & 21,52 & 16,90 \\
\hline 8 & SAFRA & Privado & 12,51 & 13,93 & 13,75 & 13,24 & 12,08 & 13,74 & 13,21 \\
\hline 9 & HSBC & Privado & 13,96 & 12,81 & 13,17 & 12,34 & 12,25 & 12,59 & 12,85 \\
\hline 10 & VOTORANTIM & Privado & 15,72 & 14,28 & 19,94 & 20,10 & 15,40 & 13,66 & 16,52 \\
\hline 11 & NOSSA CAIXA & Público & 24,86 & 27,64 & 27,15 & 23,79 & 18,19 & 25,51 & 24,52 \\
\hline 12 & CITIBANK & Privado & 14,21 & 13,79 & 15,78 & 14,53 & 14,69 & 11,73 & 14,12 \\
\hline 13 & BANKBOSTON & Privado & 15,64 & 19,08 & 23,92 & 16,86 & 11,84 & 11,02 & 16,39 \\
\hline 15 & BANRISUL & Público & 18,88 & 18,49 & 15,45 & 14,30 & 14,46 & 17,72 & 16,55 \\
\hline 16 & BNP PARIBAS & Privado & 19,27 & 15,46 & 19,13 & 15,71 & 11,27 & 15,69 & 16,09 \\
\hline 17 & BNB & Público & 19,03 & 17,44 & 20,84 & 23,77 & 16,82 & 13,19 & 18,52 \\
\hline 18 & JP MORGAN CHASE & Privado & 15,83 & 13,83 & 18,71 & 16,69 & 20,93 & 32,11 & 19,68 \\
\hline 19 & ALFA & Privado & 19,26 & 20,73 & 20,04 & 22,82 & 20,65 & 21,74 & 20,87 \\
\hline 20 & DEUTSCHE & Privado & 16,38 & 12,80 & 13,37 & 22,05 & 14,85 & 29,32 & 18,13 \\
\hline 22 & PACTUAL & Privado & 16,48 & 17,22 & 17,04 & 18,39 & 22,50 & 34,45 & 21,01 \\
\hline 23 & $B I C$ & Privado & 12,54 & 17,07 & 11,75 & 11,39 & 14,00 & 13,58 & 13,39 \\
\hline 24 & FIBRA & Privado & 15,85 & 13,80 & 17,45 & 18,85 & 20,98 & 24,09 & 18,50 \\
\hline 25 & BASA & Público & 38,75 & 44,75 & 51,42 & 58,62 & 50,85 & 15,34 & 43,29 \\
\hline 26 & BANESTES & Público & 20,21 & 15,90 & 17,01 & 12,53 & 14,66 & 15,15 & 15,91 \\
\hline 27 & BESC & Público & 41,01 & 37,09 & 36,16 & 30,90 & 178,43 & 155,73 & 79,89 \\
\hline 29 & MERCANTIL DO BRASIL & Privado & 12,83 & 12,94 & 12,64 & 13,36 & 12,49 & 14,34 & 13,10 \\
\hline 30 & RABOBANK & Privado & 12,24 & 14,62 & 15,29 & 14,35 & 11,52 & 13,53 & 13,59 \\
\hline 31 & ABC-BRASIL & Privado & 13,42 & 13,66 & 15,92 & 16,53 & 11,18 & 13,16 & 13,98 \\
\hline 32 & SS & Privado & 11,38 & 13,38 & 11,89 & 11,02 & 11,07 & 11,17 & 11,65 \\
\hline 35 & BRB & Público & 15,89 & 16,86 & 18,99 & 18,84 & 19,95 & 17,20 & 17,96 \\
\hline 36 & ING & Privado & 18,62 & 21,65 & 52,81 & 21,35 & 18,56 & 54,49 & 31,25 \\
\hline 39 & $\mathrm{BMC}$ & Privado & 15,08 & 19,26 & 13,63 & 16,99 & 15,83 & 14,40 & 15,87 \\
\hline 40 & RURAL & Privado & 15,54 & 14,17 & 14,58 & 12,05 & 11,76 & 15,21 & 13,89 \\
\hline 48 & DRESDNER & Privado & 24,98 & 26,39 & 36,93 & 26,74 & 14,28 & 14,44 & 23,96 \\
\hline
\end{tabular}


- Bancos Privados: Bradesco, Itaú, Unibanco, Santander Banespa, ABN Amro, Safra, HSBC, Votorantim, Citibank, BankBoston, BNP PARIBAS, JP Morgan Chase, ALFA, Deutsche , Pactual, BIC, FIBRA, Mercantil do Brasil, Rabobank, ABC-BRASIL , SS, ING, BMC, Rural e Dresdner.

\section{Tabela 3 - Média e Desvio Padrão do índice de Basiléia por Tipo de Controle Acionário - 2001 a 2006}

\begin{tabular}{c|c|c}
\hline \multirow{2}{*}{ Período } & \multicolumn{2}{|c}{ Média } \\
\cline { 2 - 3 } & Público & Privado \\
\hline junho-01 & $31,85 \%$ & $18,39 \%$ \\
junho-02 & $37,62 \%$ & $14,80 \%$ \\
junho-03 & $23,89 \%$ & $16,66 \%$ \\
junho-04 & $24,33 \%$ & $18,69 \%$ \\
junho-05 & $23,51 \%$ & $16,25 \%$ \\
junho-06 & $24,63 \%$ & $15,58 \%$ \\
\hline \multirow{2}{*}{ Período } & \multicolumn{2}{|c}{ Desvio Padrão } \\
\cline { 2 - 3 } & Público & Privado \\
\hline junho-01 & $46,62 \%$ & $9,98 \%$ \\
\hline junho-02 & $54,13 \%$ & $3,40 \%$ \\
\hline junho-03 & $14,29 \%$ & $3,81 \%$ \\
\hline junho-04 & $12,24 \%$ & $8,73 \%$ \\
\hline junho-05 & $10,67 \%$ & $3,31 \%$ \\
\hline junho-06 & $9,24 \%$ & $2,93 \%$ \\
\hline
\end{tabular}

Os dados disponibilizados pelo Banco Central mostram, como mencionado anteriormente, que as instituições encontram-se aderentes ao limite estabelecido de $11 \%$. Os bancos públicos federais são os mais bem classificados no ranking do Banco Central em julho de 2006. Ao estudar mais detidamente os dois grupos, verifica-se que os bancos privados possuem, nos períodos estudados, um índice mais homogêneo, haja vista que os índices dessas instituições são relativamente próximos entre si. Esta afirmação pode ser verificada pelo valor do desvio-padrão do índice (Tabela 3) para cada ano.

Já nos bancos públicos há uma variabilidade maior, com a presença de valores bem maiores que no restante do grupo, como é o caso do BESC. Tal fato acarreta um desvio padrão mais elevado, notadamente para os anos de 2001 e 2002, o que contribuiu para o incremento observado no índice de Basiléia entre os bancos públicos.

Analisando a Tabela 3, torna-se patente a presença de valores discrepantes, isto é, de valores que são muito divergentes do valor médio do grupo, principalmente nos bancos cujo controle compete ao Estado - com desvio padrão de $46 \%$ do valor médio -, fato que pode induzir a uma impressão contrária à hipótese levantada por este estudo. Todavia, por apresentar as referidas discrepâncias, constata-se a inaplicabilidade dos métodos estatísticos tradicionais, denominados paramétricos, pois os rígidos pressupostos desses não são atendidos pelo conjunto de dados amostrais. Decidiu-se, assim, adotar um teste não paramétrico para 
o estudo empírico, haja vista a maior flexibilidade deste em relação aos métodos tradicionais, principalmente no que concerne à observância de pressupostos menos rígidos.

Gráfico 1 - Valor Médio de índice de Basiléia por controle acionário - entre 2001 e 2006

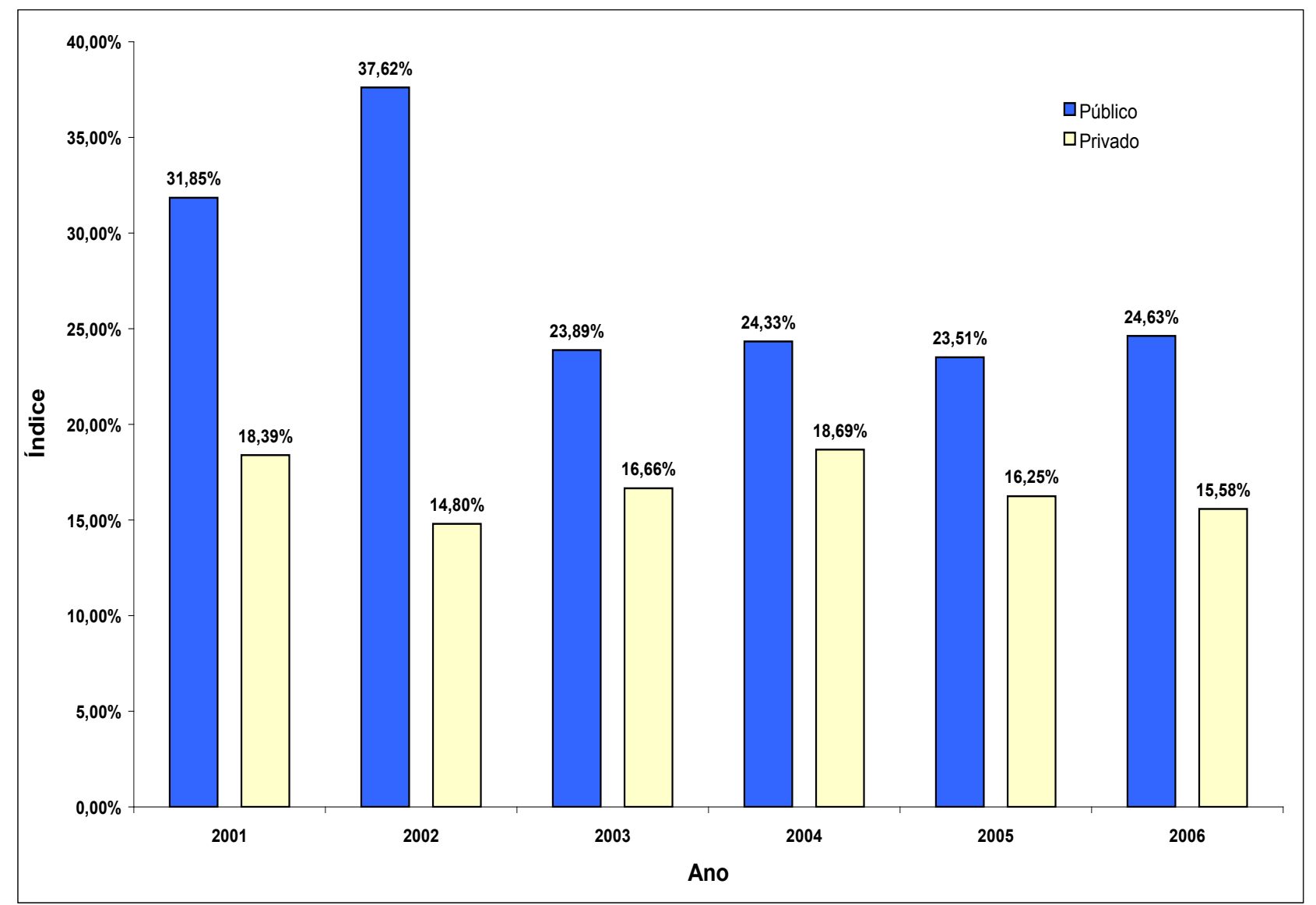

Por ser a média uma medida muito influenciada por valores discrepantes, sua mera observação pode levar à conclusão precipitada de que as amostras são distintas entre si, o que rejeitaria a hipótese nula. Contudo, ao se analisar a mediana - medida menos influenciada por valores discrepantes -, observa-se uma maior homogeneidade entre os grupos.

Tabela 4 - Valor Mediano do índice de Basiléia pelo Tipo do Controle Acionário 2001 a 2006

\begin{tabular}{c|c|c}
\hline \multirow{2}{*}{ Período } & \multicolumn{2}{c}{ Mediana } \\
\cline { 2 - 3 } & Público & Privado \\
\hline junho-01 & $15,34 \%$ & $14,34 \%$ \\
junho-02 & $16,82 \%$ & $14,28 \%$ \\
junho-03 & $18,84 \%$ & $16,53 \%$ \\
junho-04 & $18,99 \%$ & $16,73 \%$ \\
junho-05 & $17,67 \%$ & $15,46 \%$ \\
junho-06 & $20,21 \%$ & $15,54 \%$ \\
\hline
\end{tabular}


A Tabela acima mostra que o índice de Basiléia não é tão distinto de um grupo para o outro quando se observa a mediana. Para se verificar se existe diferença significativa, foi escolhido o Teste de Mann-Witney. As explicações sobre o teste e os resultados são mostradas a seguir.

\subsection{O Teste de Mann-Whitney}

Conforme dito anteriormente, deseja-se verificar se a diferença obtida no resultado da aplicação no índice de Basiléia é diferenciada segundo o tipo do Controle Acionário do banco estudado, ou seja, busca-se a reposta para a seguinte indagação: teria o índice um comportamento distinto explicado somente pelo fato de o controle ser estatal ou privado? O teste indicado para essa análise é conhecido como teste não paramétrico de Mann-Whitney.

O Teste de Mann-Whitney é utilizado para verificar se duas amostras pertencem ou não à mesma população ou se em uma amostra aleatória subdividida em dois grupos existiria distinção entre as médias ou a mediana dos dois grupos. A idéia do teste é bastante simples para o problema de duas amostras, consistindo na combinação das duas em uma única amostra ordenada do menor para o maior valor sem, entretanto, levar em conta de qual amostra os valores são provenientes. Então a estatística seria a soma dos postos dos valores para uma das populações (no presente caso, público ou privado).

Se a soma for muito pequena (ou muito grande), isto seria um indicativo de que os valores para essa população são menores (ou maiores, dependendo do caso) do que os valores da outra população. Então a hipótese nula - a de que não haveria diferença entre as populações - pode ser rejeitada se o posto associado com uma das amostras tende a ser maior que a outra amostra.

\subsubsection{Pressupostos para a correta aplicação do Teste de Mann-Whitney}

1. Ambas as amostras são aleatórias em suas respectivas populações.

2. As amostras são mutuamente independentes entre as duas amostras.

3. A escala de mensuração é no mínimo ordinal.

No conjunto de dados em que o estudo é baseado, todos esses pressupostos estão sendo satisfeitos, o que possibilita a utilização do teste de M-W (abreviação de MannWhitney).

\subsubsection{Estatística-teste}

A estatística-teste, quando não há empates, ou apenas poucos empates, é a soma dos postos obtidos da amostra da população.

$$
T=\sum_{i=1}^{n} R\left(X_{i}\right)
$$


Na hipótese de ocorrer uma grande quantidade de empates, subtrai-se a média de T e divide-se pelo desvio padrão mostrado no denominador, conforme preconiza a fórmula:

$$
T_{1}=\frac{T-n \frac{N+1}{2}}{\sqrt{\frac{n \cdot m}{N(N-1)} \cdot \sum_{i=1}^{N} R_{i}{ }^{2}-\frac{n \cdot m(N+1)}{4(N-1)}}}
$$

onde

$$
\begin{aligned}
& n=\text { tamanho da amostra } 1 \\
& m=\text { tamanho da amostra } 2 \\
& N=\text { soma das amostras } 1 \text { e } 2(n+m) \\
& \sum_{i=1}^{N} R^{2}=\text { Soma dos quadrados d todos } 8 \text { N postos }
\end{aligned}
$$

\subsubsection{Hipótese}

$\mathrm{H}_{0}=$ As populações possuem distribuições idênticas $(E(x)=E(x))$.

$\mathrm{H}_{\mathrm{a}}=$ Há diferença nos resultados das duas amostras $(\mathrm{E}(x) \neq \mathrm{E}(x))$.

\subsubsection{Regra de decisão}

Conforme já mencionado, a hipótese nula do teste é a de que as duas amostras são provenientes da mesma população, ou seja, não existe diferença entre os resultados dos bancos públicos e aqueles obtidos para os bancos privados. Rejeita-se a hipótese nula com um nível de significância de $\square=5 \%$, se o $p$-valor for menor que $\square$.

\subsubsection{Resultados}

Conforme já explanado anteriormente, e evidenciado adiante no Gráfico 2, os valores médios do índice de Basiléia para os dois grupos em estudo são muito similares, mas a ocorrência de valores discrepantes inexoravelmente nos induz a um valor da estatística do teste próxima da rejeição, isto é, um p-valor de $4 \%$.

\section{Gráfico 2 - Distribuição do valor médio do Índice de Basiléia pelo controle acionário - entre 2001 e 2006}
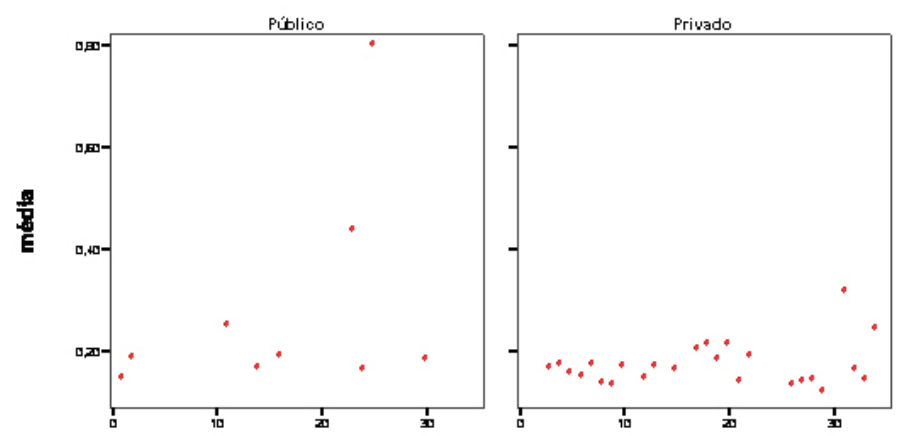
Todavia, tal valor é muito próximo do limite de decisão. Agrava-se a isso os indícios de que há influência de valores discrepantes, o que nos induz a aceitar a hipótese nula de igualdade entre os grupos. Ou seja, não existiria uma distinção, estatisticamente significativa, do valor médio do índice de Basiléia no período de 2001 a 2006 segundo o tipo do Controle Acionário dos bancos participantes do Sistema Financeiro Brasileiro.

Tabela 5 - Valores da média e a soma dos postos para os dois tipos de controle acionário.

\begin{tabular}{|l|r|r|r|}
\hline $\begin{array}{c}\text { Tipo do Controle } \\
\text { Acionario }\end{array}$ & | & Mean Rank & Sum of Ranks \\
\hline Público & 9 & 23,33 & 210,00 \\
Privado & 25 & 15,40 & 385,00 \\
Total & 34 & & \\
\hline
\end{tabular}

Tabela 6 - Resultados do Teste de Mann-Whitney para o tipo de Controle Acionário.

\begin{tabular}{|l|r|}
\hline & \multicolumn{1}{|c|}{ Valores } \\
\hline Mann-Whitney & 60,000 \\
$Z$ & $-2,050$ \\
p-valor &, 040 \\
\hline
\end{tabular}

Deve-se fazer uma consideração sobre o $p$-valor e a proximidade do nível de significância de 5\% (0,040): este resultado indica que o resultado da amostra encontra-se muito próximo à região de rejeição. Para verificar realmente se existe ou não diferença neste ponto em particular, seria recomendada uma nova aplicação do tratamento, só que dessa vez em uma amostra maior, o que resultaria em uma maior confiabilidade a esse resultado apresentado acima. Face ao resultado inconclusivo descrito até aqui, procedeu-se à ampliação da amostra no intuito de testar as hipóteses com maior grau de segurança. Assim, a amostra passou a contemplar períodos trimestrais, de março de 2001 a setembro de 2006, o que resultou em 18 períodos abordados, o triplo da amostra original. Não obstante esse considerável aumento, manteve-se a lista dos 50 maiores bancos, agora na posição atualizada de setembro de 2006, segundo disponibilizou o Bacen. Desses 50 bancos, 29 permaneceram na lista durante todo o período abordado, ininterruptamente. Configuram, assim, o novo objeto de estudo.

A nova amostragem ficou assim estabelecida, segundo o tipo de Controle Acionário:

- Bancos Públicos: Banco do Brasil (BB), Caixa Econômica Federal (CEF), Nossa Caixa, Banco do Estado do Rio Grande do Sul (Banrisul), Banco do Nordeste do Brasil (BNB), Banco da Amazônia (BASA), Banco do Estado do Espírito Santo (Banestes) e Banco de Brasília (BRB).

- Bancos Privados: Bradesco, Itaú, Unibanco, Santander Banespa, ABN Amro, Safra, HSBC, Votorantim, Citibank, JP Morgan Chase, ALFA, Deutsche, Pactual, BIC, FIBRA, Mercantil do Brasil, Rabobank, ABC-BRASIL, SS e BMC.

Os bancos privados listados abaixo não compõem a amostra porque, em um ou mais 
trimestres estudados, não se encontravam entre os 50 maiores bancos segundo o Bacen:

- Bancos Privados: ING, BBM, Credit Suisse, BNP Paribas, BMG, Bancoob, Ibibank, Clássico, Daycoval, Pine, Sofisa, Westlb, Bansicredi, Cruzeiro do Sul, UBS Warburg, Banif, Banco John Deere, BGN, Schahin.

- Banco Público: BESC. As razões por que retiramos este banco da amostra são exaradas na conclusão do trabalho, em que pese o fato deste haver permanecido, ininterruptamente, entre os 50 maiores bancos durante todos os 18 trimestres estudados.

Desse modo, as Tabelas 7 e 8 contém toda a nova amostra, compreendendo 18 trimestres. A Tabela 7 abarca os anos de 2001 a 2003, e a Tabela 8, os anos de 2004 a 2006, além de conter a média do Índice de Basiléia para todo o período abordado.

\section{Tabela 7 - Índice de Basiléia para 28 Instituições Bancárias do Brasil - março de 2001 a setembro de 2003}

\begin{tabular}{|c|c|c|c|c|c|c|c|c|c|c|}
\hline \multirow{2}{*}{ BANCO } & \multirow{2}{*}{ TC } & \multicolumn{9}{|c|}{ Índice de Basíleia } \\
\hline & & set/03 & jun/03 & mar/03 & set/02 & jun/02 & mar/02 & set/01 & jun/01 & $\mathrm{mar} / 01$ \\
\hline$\overline{B B}$ & Público & $14,30 \%$ & $13,79 \%$ & $13,32 \%$ & $10,86 \%$ & $11,53 \%$ & $13,05 \%$ & $12,28 \%$ & $11,95 \%$ & $7,90 \%$ \\
\hline CEF & Público & $18,85 \%$ & $18,43 \%$ & $17,20 \%$ & $14,05 \%$ & $13,68 \%$ & $13,71 \%$ & $14,79 \%$ & $14,84 \%$ & $4,93 \%$ \\
\hline NOSSACAIXA & Público & $25,12 \%$ & $23,79 \%$ & $24,50 \%$ & $16,43 \%$ & $18,19 \%$ & $20,33 \%$ & $18,36 \%$ & $25,51 \%$ & $25,86 \%$ \\
\hline BANRISUL & Público & $16,50 \%$ & $14,30 \%$ & $13,37 \%$ & $12,50 \%$ & $14,46 \%$ & $15,73 \%$ & $17,75 \%$ & $17,72 \%$ & $18,44 \%$ \\
\hline BNB & Público & $24,29 \%$ & $23,77 \%$ & $21,82 \%$ & $16,04 \%$ & $16,82 \%$ & $16,33 \%$ & $10,54 \%$ & $13,19 \%$ & $7,03 \%$ \\
\hline BASA & Público & $54,76 \%$ & $58,62 \%$ & $56,81 \%$ & $63,91 \%$ & $50,85 \%$ & $64,15 \%$ & $19,48 \%$ & $15,34 \%$ & $12,55 \%$ \\
\hline BANES & Público & $12,83 \%$ & $12,53 \%$ & $11,95 \%$ & $13,47 \%$ & $14,66 \%$ & $13,99 \%$ & $15,27 \%$ & $15,15 \%$ & $16,17 \%$ \\
\hline BRB & Público & $19,78 \%$ & $18,84 \%$ & $18,48 \%$ & $16,84 \%$ & $19,95 \%$ & $19,55 \%$ & $16,84 \%$ & $17,20 \%$ & $17,77 \%$ \\
\hline ITAU & Privado & $20,74 \%$ & $17,07 \%$ & $18,56 \%$ & $18,67 \%$ & $15,73 \%$ & $17,43 \%$ & $13,60 \%$ & $14,23 \%$ & $14,11 \%$ \\
\hline BRAD & Privado & $18,37 \%$ & $16,36 \%$ & $19,68 \%$ & $15,55 \%$ & $14,31 \%$ & $15,09 \%$ & $13,16 \%$ & $13,30 \%$ & $13,33 \%$ \\
\hline UNIBANCO & Privado & $17,33 \%$ & $16,72 \%$ & $14,94 \%$ & $12,28 \%$ & $13,42 \%$ & $13,80 \%$ & $13,30 \%$ & $14,40 \%$ & $14,91 \%$ \\
\hline ABN AMRO & Privado & $17,89 \%$ & $14,64 \%$ & $15,17 \%$ & $13,60 \%$ & $14,95 \%$ & $16,52 \%$ & $17,56 \%$ & $21,52 \%$ & $20,59 \%$ \\
\hline SANTANDER & Privado & $17,40 \%$ & $16,39 \%$ & $18,71 \%$ & $11,81 \%$ & $13,56 \%$ & $15,57 \%$ & $12,28 \%$ & $11,82 \%$ & $12,73 \%$ \\
\hline SAFRA & Privado & $16,11 \%$ & $13,24 \%$ & $13,05 \%$ & $12,13 \%$ & $12,08 \%$ & $12,29 \%$ & $11,42 \%$ & $13,74 \%$ & $13,14 \%$ \\
\hline HSBC & Privado & $14,20 \%$ & $12,34 \%$ & $13,10 \%$ & $12,06 \%$ & $12,25 \%$ & $12,95 \%$ & $12,96 \%$ & $12,59 \%$ & $12,10 \%$ \\
\hline VOTORANTIM & Privado & $24,43 \%$ & $20,10 \%$ & $18,29 \%$ & $15,93 \%$ & $15,40 \%$ & $18,52 \%$ & $14,22 \%$ & $13,66 \%$ & $14,04 \%$ \\
\hline CITIBANK & Privado & $22,33 \%$ & $14,53 \%$ & $18,14 \%$ & $14,85 \%$ & $14,69 \%$ & $13,08 \%$ & $12,29 \%$ & $11,73 \%$ & $12,04 \%$ \\
\hline PACTUAL & Privado & $16,13 \%$ & $18,39 \%$ & $15,77 \%$ & $20,89 \%$ & $22,50 \%$ & $18,18 \%$ & $16,22 \%$ & $34,45 \%$ & $30,95 \%$ \\
\hline ALFA & Privado & $21,81 \%$ & $22,82 \%$ & $20,88 \%$ & $17,73 \%$ & $20,65 \%$ & $21,75 \%$ & $21,05 \%$ & $21,74 \%$ & $23,80 \%$ \\
\hline DEUTS & Privado & $20,49 \%$ & $22,05 \%$ & $25,74 \%$ & $16,78 \%$ & $14,85 \%$ & $11,55 \%$ & $7 \%$ & $29,32 \%$ & $25,07 \%$ \\
\hline JP MORGAN & Privado & $18,21 \%$ & $16,69 \%$ & $12,76 \%$ & $12,39 \%$ & $20,93 \%$ & $18,41 \%$ & $15,52 \%$ & $32,11 \%$ & $26,16 \%$ \\
\hline BIC & Privado & $12,29 \%$ & $11,39 \%$ & $12,03 \%$ & $11,51 \%$ & $14,00 \%$ & $15,90 \%$ & $14,50 \%$ & $13,58 \%$ & $13,67 \%$ \\
\hline FIBRA & Privado & $21,08 \%$ & $18,85 \%$ & $17,08 \%$ & $15,16 \%$ & $20,98 \%$ & $24,60 \%$ & $16,46 \%$ & $24,09 \%$ & $28,50 \%$ \\
\hline MERCANTIL L & Privado & $13,87 \%$ & $13,36 \%$ & $13,57 \%$ & $12,07 \%$ & $12,49 \%$ & $13,13 \%$ & $13,84 \%$ & $14,34 \%$ & $14,52 \%$ \\
\hline RABOBANK & Privado & $11,92 \%$ & $14,35 \%$ & $11,97 \%$ & $11,07 \%$ & $11,52 \%$ & $16,08 \%$ & $11,50 \%$ & $13,53 \%$ & $12,00 \%$ \\
\hline SS & Privado & $11,02 \%$ & $11,02 \%$ & $11,02 \%$ & $11,33 \%$ & $11,07 \%$ & $11,07 \%$ & $11,41 \%$ & $11,17 \%$ & $12,01 \%$ \\
\hline$A B C-B$ & Privado & $19,74 \%$ & $16,53 \%$ & $17,17 \%$ & $11,36 \%$ & $11,18 \%$ & $12,77 \%$ & $10,62 \%$ & $13,16 \%$ & $13,16 \%$ \\
\hline BMC & Privado & $15,89 \%$ & $16,99 \%$ & $13,41 \%$ & $13,30 \%$ & $15,83 \%$ & $14,16 \%$ & $16,00 \%$ & $14,40 \%$ & $13,88 \%$ \\
\hline
\end{tabular}

FONTE: Banco Central do Brasil - BACEN

Em relação à Média e ao Desvio-Padrão da nova amostra, os resultados encontramse expressos na Tabela 9, na próxima página, ao passo que a distribuição do valor médio do Índice de Basiléia pelo controle acionário é apresentada logo após, no Gráfico 3. 
Analisando os valores provenientes da Tabela 9, observa-se que, em que pese a maior quantidade de bancos cujo controle acionário é privado, a estrutura deste grupo apresenta-se mais homogênea, isto é, o valor do índice de Basiléia das instituições privadas não difere significativamente uns dos outros, isso fica representado no valor do desvio padrão para cada trimestre avaliado.

Uma maneira adequada de se mostrar a maior homogeneidade do valor médio das instituições privadas - em oposição à maior dispersão dos valores médios das instituições públicas - consiste na utilização do gráfico "Box-plot", conforme expomos abaixo por meio do Gráfico 4.

\section{Tabela 8 - Índice de Basiléia para 28 Instituições Bancárias do Brasil - março de 2004 a setembro de 2006 e a média entre 2001 e 2006}

\begin{tabular}{|c|c|c|c|c|c|c|c|c|c|c|c|}
\hline \multirow{2}{*}{ BANCO } & \multirow{2}{*}{ TC } & \multicolumn{9}{|c|}{ Índice de Basíleia } & \multirow{2}{*}{ Média } \\
\hline & & set/06 & jun/06 & $\operatorname{mar} / 06$ & set/05 & jun/05 & mar/05 & set/04 & jun/04 & $\operatorname{mar} / 04$ & \\
\hline BB & Público & $17,69 \%$ & $17,28 \%$ & $18,23 \%$ & $17,36 \%$ & $5,72 \%$ & $15,56 \%$ & $15,64 \%$ & $14,39 \%$ & $14,24 \%$ & $14,17 \%$ \\
\hline CEF & blico & $26,24 \%$ & $25,72 \%$ & $29,23 \%$ & $18,32 \%$ & $17,67 \%$ & $19,41 \%$ & $18,35 \%$ & $17,58 \%$ & $19,40 \%$ & $17,91 \%$ \\
\hline NOSSACAIXA & úblico & $23,53 \%$ & $24,86 \%$ & $28,47 \%$ & $29,07 \%$ & $27,64 \%$ & $28,01 \%$ & $27,74 \%$ & $27,15 \%$ & $28,12 \%$ & $24,59 \%$ \\
\hline BANRISUL & Público & $20,68 \%$ & $18,88 \%$ & $18,95 \%$ & $19,31 \%$ & $18,49 \%$ & $17,17 \%$ & $14,81 \%$ & $15,45 \%$ & $16,94 \%$ & $16,75 \%$ \\
\hline BNB & Público & $18,56 \%$ & $19,03 \%$ & $19,14 \%$ & $18,38 \%$ & $17,44 \%$ & $19,19 \%$ & $21,53 \%$ & $20,84 \%$ & $21,76 \%$ & $18,09 \%$ \\
\hline BASA & Público & $36,72 \%$ & $38,75 \%$ & $40,77 \%$ & $44,01 \%$ & $44,75 \%$ & $47,03 \%$ & $51,40 \%$ & $51,42 \%$ & $55,42 \%$ & $44,82 \%$ \\
\hline BANES & Público & $20,15 \%$ & $20,21 \%$ & $19,81 \%$ & $17,44 \%$ & $15,90 \%$ & $15,83 \%$ & $15,72 \%$ & $17,01 \%$ & $17,11 \%$ & $15,84 \%$ \\
\hline BRB & Público & $16,26 \%$ & $15,89 \%$ & $16,98 \%$ & $17,51 \%$ & $16,86 \%$ & $16,42 \%$ & $18,13 \%$ & $18,99 \%$ & $18,94 \%$ & $17,85 \%$ \\
\hline ITAU & Privado & $17,87 \%$ & $16,06 \%$ & $16,66 \%$ & $17,33 \%$ & $17,89 \%$ & $18,11 \%$ & $18,98 \%$ & $19,79 \%$ & $19,18 \%$ & $17,33 \%$ \\
\hline BRADE & Privado & $18,37 \%$ & $18,67 \%$ & $19,04 \%$ & $17,73 \%$ & $18,21 \%$ & $17,11 \%$ & $19,89 \%$ & $18,07 \%$ & $18,91 \%$ & $16,95 \%$ \\
\hline & Privado & $15,53 \%$ & $15,01 \%$ & 16 & $16,47 \%$ & 16 & & $15,36 \%$ & $16,73 \%$ & $3 \%$ & \\
\hline ABN & Privado & $13,70 \%$ & $14,42 \%$ & $15,16 \%$ & $17,19 \%$ & $17,45 \%$ & $18,30 \%$ & $18,32 \%$ & $18,41 \%$ & $20,57 \%$ & $17,00 \%$ \\
\hline SANTANDER & Privado & $15,57 \%$ & $13,61 \%$ & $13,24 \%$ & $14,91 \%$ & $15,60 \%$ & $14,47 \%$ & $17,04 \%$ & $16,40 \%$ & $18,40 \%$ & $14,97 \%$ \\
\hline SAFRA & Privado & $12,15 \%$ & $12,51 \%$ & $12,44 \%$ & $13,68 \%$ & $13,93 \%$ & $13,09 \%$ & $13,04 \%$ & $13,75 \%$ & $17,88 \%$ & $13,32 \%$ \\
\hline HSBC & Privado & $13,34 \%$ & $13,96 \%$ & $14,32 \%$ & $12,64 \%$ & $12,81 \%$ & $12,71 \%$ & $12,77 \%$ & $13,17 \%$ & $14,33 \%$ & $13,03 \%$ \\
\hline VOTOR & Privado & $17,32 \%$ & $15,72 \%$ & $17,64 \%$ & $15,41 \%$ & $14,28 \%$ & $16,97 \%$ & $20,24 \%$ & $19,94 \%$ & $18,88 \%$ & $17,28 \%$ \\
\hline CITIBANK & Privado & $14,75 \%$ & $14,21 \%$ & $11,73 \%$ & $12,08 \%$ & $13,79 \%$ & $13,77 \%$ & $19,05 \%$ & $15,78 \%$ & $18,46 \%$ & $14,85 \%$ \\
\hline PACTU & Privado & $14,25 \%$ & $16,48 \%$ & $20,93 \%$ & $11,26 \%$ & $17,22 \%$ & $13,66 \%$ & $15,96 \%$ & $17,04 \%$ & $19,04 \%$ & $18,85 \%$ \\
\hline ALFA & Privado & $17,85 \%$ & $19,26 \%$ & $19,30 \%$ & $20,96 \%$ & $20,73 \%$ & $21,61 \%$ & $18,98 \%$ & $20,04 \%$ & $21,98 \%$ & $20,72 \%$ \\
\hline DEUTS & Privado & $20,52 \%$ & $16,38 \%$ & $13,84 \%$ & $15,05 \%$ & $12,80 \%$ & $14,44 \%$ & $19,78 \%$ & $13,37 \%$ & $15,15 \%$ & $18,16 \%$ \\
\hline JP MORGAN CHASE & Privado & $22,87 \%$ & $15,83 \%$ & $15,38 \%$ & $14,43 \%$ & $13,83 \%$ & $16,83 \%$ & $16,95 \%$ & $18,71 \%$ & $18,74 \%$ & $18,15 \%$ \\
\hline $\mathrm{BIC}$ & Privado & $17,59 \%$ & $12,54 \%$ & $14,70 \%$ & $17,91 \%$ & $17,07 \%$ & $17,25 \%$ & $12,54 \%$ & $11,75 \%$ & $13,03 \%$ & $14,07 \%$ \\
\hline FIBRA & Privado & $14,01 \%$ & $15,85 \%$ & $14,72 \%$ & $12,44 \%$ & $13,80 \%$ & $17,54 \%$ & $21,11 \%$ & $17,45 \%$ & $22,64 \%$ & $18,69 \%$ \\
\hline MERCA & Privado & $12,31 \%$ & $12,83 \%$ & $13,53 \%$ & $12,44 \%$ & $12,94 \%$ & $13,70 \%$ & $12,36 \%$ & $12,64 \%$ & $13,48 \%$ & $13,19 \%$ \\
\hline RABOBANK & Privado & $11,01 \%$ & $12,24 \%$ & $12,33 \%$ & $13,81 \%$ & $14,62 \%$ & $11,18 \%$ & $14,49 \%$ & $15,29 \%$ & $12,96 \%$ & $12,88 \%$ \\
\hline SS & Privado & $11,08 \%$ & $11,38 \%$ & $11,99 \%$ & $13,10 \%$ & $13,38 \%$ & $13,20 \%$ & $11,03 \%$ & $11,89 \%$ & $11,01 \%$ & $11,62 \%$ \\
\hline$A B C-B$ & Privado & $13,98 \%$ & $13,42 \%$ & $13,97 \%$ & $14,86 \%$ & $13,66 \%$ & $16,60 \%$ & $14,69 \%$ & $15,92 \%$ & $19,98 \%$ & $14,60 \%$ \\
\hline $\mathrm{BMC}$ & Privado & $15,98 \%$ & $15,08 \%$ & $19,17 \%$ & $20,13 \%$ & $19,26 \%$ & $20,17 \%$ & $12,48 \%$ & $13,63 \%$ & $14,92 \%$ & $15,82 \%$ \\
\hline
\end{tabular}

Fonte: Banco Central do Brasil - BACEN

A partir do que já fora exposto no decorrer deste trabalho, notadamente no que concerne à aplicação do teste de Mann-Whitney, e com base nos mesmos pressupostos enunciados à pág. 18, para se testar a hipótese nula será novamente apresentada a Regra de Decisão - idêntica àquela apresentada na pág. 20 -, bem como os resultados obtidos após ter sido ampliada a amostra. 


\section{repc}

\subsubsection{Regra de Decisão (amostra ampliada)}

A hipótese nula do teste é a de que as duas amostras são provenientes da mesma população, isto é, não existiria diferença entre os resultados dos bancos públicos e privados. Rejeita-se a hipótese nula com um nível de significância de $\square=5 \%$ se o $p$-valor for menor que $5 \%$.

Tabela 9 - Média e Desvio Padrão do Índice de Basiléia pelo Tipo do Controle Acionário - entre 2001 e 2006

\begin{tabular}{c|c|c|c|c|c|c}
\hline \multirow{2}{*}{ Periodo } & \multicolumn{3}{|c|}{ Média } & \multicolumn{3}{c}{ Desvio Padrão } \\
\cline { 2 - 7 } & \multicolumn{3}{|c|}{ Controle Acionario } & \multicolumn{3}{c}{ Controle Acionario } \\
\cline { 2 - 7 } & Público & Privado & Total & Privado & Total \\
\hline set/06 & $22,48 \%$ & $15,50 \%$ & $17,50 \%$ & $6,59 \%$ & $3,10 \%$ & $5,32 \%$ \\
jun/06 & $22,58 \%$ & $14,77 \%$ & $17,00 \%$ & $7,38 \%$ & $2,08 \%$ & $5,48 \%$ \\
mar/06 & $23,95 \%$ & $15,32 \%$ & $17,79 \%$ & $8,26 \%$ & $2,70 \%$ & $6,21 \%$ \\
set/05 & $22,68 \%$ & $15,19 \%$ & $17,33 \%$ & $9,47 \%$ & $2,69 \%$ & $6,34 \%$ \\
jun/05 & $21,81 \%$ & $15,47 \%$ & $17,28 \%$ & $10,03 \%$ & $2,37 \%$ & $6,21 \%$ \\
mar/05 & $22,33 \%$ & $15,85 \%$ & $17,70 \%$ & $10,76 \%$ & $2,68 \%$ & $6,63 \%$ \\
set/04 & $22,92 \%$ & $16,25 \%$ & $18,16 \%$ & $12,25 \%$ & $3,18 \%$ & $7,45 \%$ \\
jun/04 & $22,85 \%$ & $15,99 \%$ & $17,95 \%$ & $12,20 \%$ & $2,71 \%$ & $7,33 \%$ \\
mar/04 & $23,99 \%$ & $17,38 \%$ & $19,27 \%$ & $13,36 \%$ & $3,21 \%$ & $7,92 \%$ \\
set/03 & $23,30 \%$ & $17,56 \%$ & $19,20 \%$ & $13,43 \%$ & $3,69 \%$ & $7,96 \%$ \\
jun/03 & $23,01 \%$ & $16,19 \%$ & $18,14 \%$ & $15,02 \%$ & $3,22 \%$ & $8,70 \%$ \\
mar/03 & $22,18 \%$ & $16,05 \%$ & $17,80 \%$ & $14,66 \%$ & $3,68 \%$ & $8,55 \%$ \\
set/02 & $20,51 \%$ & $14,02 \%$ & $15,88 \%$ & $17,66 \%$ & $2,81 \%$ & $9,76 \%$ \\
jun/02 & $20,02 \%$ & $15,12 \%$ & $16,52 \%$ & $12,74 \%$ & $3,49 \%$ & $7,46 \%$ \\
mar/02 & $22,11 \%$ & $15,64 \%$ & $17,49 \%$ & $17,20 \%$ & $3,46 \%$ & $9,69 \%$ \\
set/01 & $15,66 \%$ & $14,38 \%$ & $14,75 \%$ & $3,08 \%$ & $2,80 \%$ & $2,88 \%$ \\
jun/01 & $16,36 \%$ & $17,44 \%$ & $17,14 \%$ & $4,15 \%$ & $7,20 \%$ & $6,42 \%$ \\
mar/01 & $13,83 \%$ & $17,04 \%$ & $16,12 \%$ & $7,06 \%$ & $6,25 \%$ & $6,53 \%$ \\
\hline
\end{tabular}

Fonte: Elaborado pelo autor

\section{Gráfico 3 - Distribuição do valor médio do índice de Basiléia pelo controle acionário} - entre 2001 e 2006

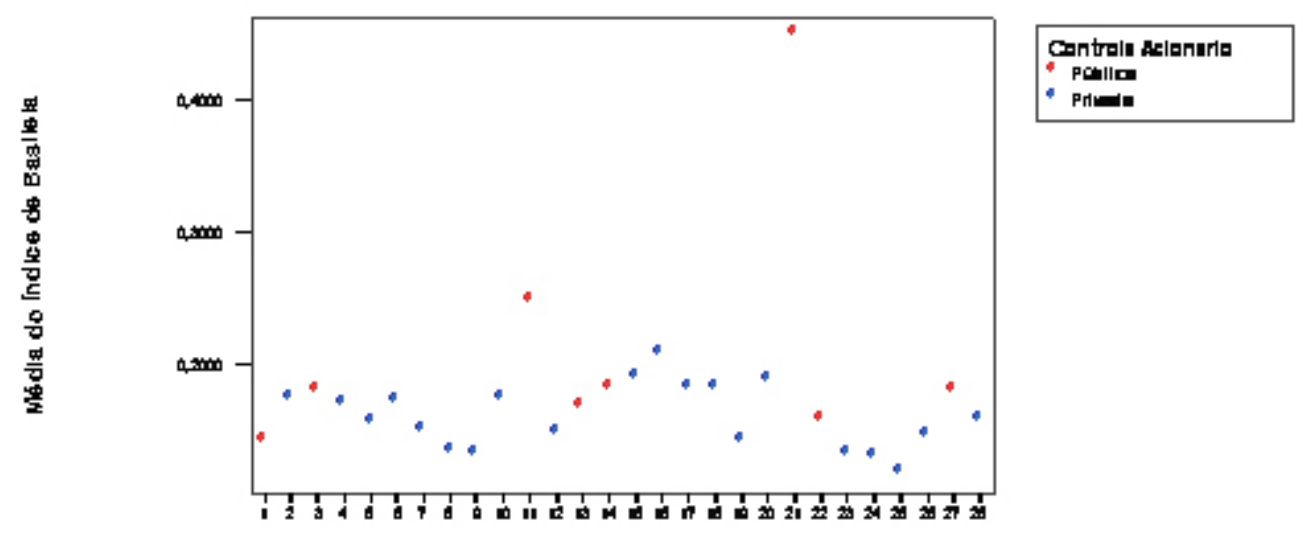




\section{repec}

\subsection{Resultados após ampliação da amostra}

Como exposto anteriormente e com auxílio do Gráfico 4 "Box-plot", os valores médios do Índice de Basiléia para os dois grupos em estudo são muito similares, mas a ocorrência de valores discrepantes influencia no valor da estatística do teste, como demonstram os índices do banco estatal BASA. Não obstante, o $p$-valor de $9,3 \%$ leva à não-rejeição da hipótese de igualdade entre os grupos. Os resultados estão dispostos abaixo, nas Tabelas 10 e 11. Ou seja, não existe uma distinção, estatisticamente significativa, do valor médio do índice de Basiléia no período compreendido entre março de 2001 e setembro de 2006, segundo o tipo do Controle Acionário dos principais bancos do Sistema Financeiro Brasileiro.

\section{Gráfico 4 - Boxplot do valor médio do Índice de Basiléia pelo controle acionário - entre 2001 e 2006}

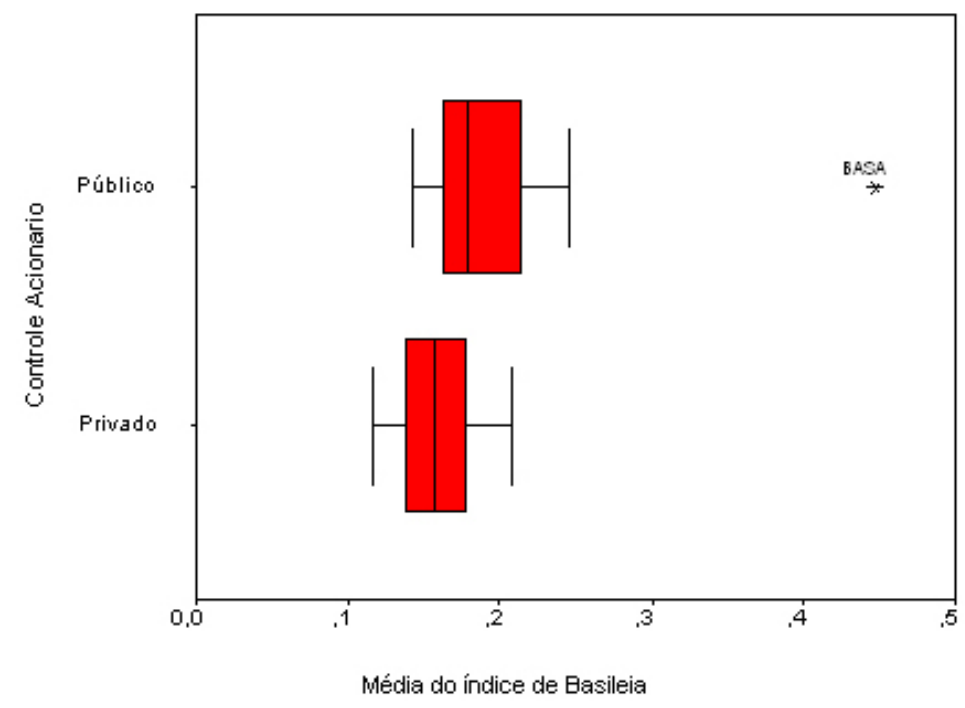

Tabela 10 - Valores da média e a soma dos postos para os dois tipos de controle acionário

\begin{tabular}{|l|r|r|r|}
\hline $\begin{array}{l}\text { Controle } \\
\text { Acionario }\end{array}$ & N & $\begin{array}{c}\text { Média dos } \\
\text { postos }\end{array}$ & $\begin{array}{c}\text { Soma dos } \\
\text { postos }\end{array}$ \\
\hline Público & 8 & 18,63 & 149,00 \\
Privado & 20 & 12,85 & 257,00 \\
Total & 28 & & \\
\hline
\end{tabular}

Tabela 11 - Resultados do Teste de Mann-Whitney para o tipo de Controle Acionário

Estatísticas de Teste b

\begin{tabular}{|l|r|}
\hline Estatística & \multicolumn{1}{|c|}{ Valor } \\
\hline Mann-'Wühitney U & 47,000 \\
Z- Normal Padrâo & $-1,678$ \\
a value &, 093 \\
\hline
\end{tabular}

b. Variável Agrupadora: Controle Acionario 


\section{repc}

\section{CONCLUSÕES}

Com base nas informações obtidas nos dois testes realizados neste trabalho, é possível concluir que, ao contrário do que era esperado, a hipótese nula não deve ser rejeitada, ou seja, não há evidências de que ambas as amostras provém da mesma população. No entanto, cabe aqui uma ressalva: os bancos públicos BASA e BESC são responsáveis pelos valores discrepantes na média observada para os bancos públicos. Seus respectivos índices de Basiléia destoam claramente da média dos demais bancos públicos. Como pode ser observado no "Box-plot", o BASA não está inserido na distribuição dos bancos públicos, configurando-se como um outlier. Mesmo assim, ele foi mantido na amostra, e, mesmo com "contaminação" provocada pelo seu índice de Basiléia, o teste resultou na aceitação da hipótese alternativa. Cumpre observar que o BASA sofreu processo de ajuste em 2002 e teve seu sistema de avaliação de risco de crédito aprovado pelo Banco Central um ano depois quando então o banco passou a obter recursos não só do Fundo Constitucional de Financiamento do Norte (FNO), mas também do Fundo de Amparo ao Trabalhador (FAT) e do Orçamento Geral da União (OGU) (Gottschalk; Sodré, 2006, p. 67).

Por sua vez, o BESC foi retirado da amostra porque sua média do Índice de Basiléia para o período estudado é de $71,83 \%$, muitíssimo acima de todos os outros bancos. Entendeu-se que a manutenção deste banco para realização do teste acabaria levando à rejeição da hipótese nula, o que não se considerou ser o mais razoável, pois significaria aceitar que apenas um banco levaria à rejeição toda a homogeneidade observada para os outros oito bancos públicos que compuseram a amostra. Por isso, decidiu-se pela sua exclusão, e não se rejeitou a hipótese de que os índices não diferem por conta do tipo de controle acionário, isto é, bancos públicos e privados tendem, no período estudado, a possuir Índices de Basiléia não estatisticamente diferenciados. Deduziu-se que o índice apresentado pelo BESC é decorrência da vultosa operação de crédito de $\mathrm{R} \$ 2,129$ bilhões que a União aportou junto a esse banco (federalização), o que ocorreu em setembro de 1999.

O estudo empírico poderia ser aprimorado se o Bacen disponibilizasse o Índice de Basiléia dos Bancos para anos mais remotos, como, por exemplo, 1997, ano em que foi imposto o percentual de $11 \%$ para o capital mínimo relativo. No entanto, o Bacen divulga o índice dos bancos somente a partir de 2001.

\section{REFERÊNCIAS}

BANCO CENTRAL DO BRASIL, 2007. 50 Maiores Bancos e o Consolidado do Sistema Financeiro Nacional. Disponível em:

<http://www.bcb.gov.br/fis/top50/port/default.asp?parmidioma=P\&id=top50>. Diversos acessos entre nov. 06 e jan. 07. 


\section{repec}

BARBETTA, Pedro Alberto. Estatística Aplicada às Ciências Sociais, 5. ed. Florianópolis: Editora da UFSC, 2002.

BUSSAB, Wilton; MORETTIN, Pedro. Estatística Básica. 5. ed. São Paulo: Saraiva, 2002.

BCBS, BASEL COMITTEE ON BANKING SUPERVISION (BCBS). Overview of The New Basel Capital Accord, BIS, Tradução elaborada pela ERNST \& YOUNG/FEBRABAN, Basiléia, 2001.

. The New Basel Capital Accord, BIS, Tradução elaborada pela ERNST \& YOUNG/ FEBRABAN, Basiléia, 2001.

GOTTSCHALK, Ricardo; SODRÉ, Maria Cecília. O Novo Acordo da Basiléia no Brasil: Impactos sobre os Bancos Públicos e Privados. Economia Política Internacional: Análise Estratégica, Campinas, Instituto de Economia/Unicamp, n.8, jan./jun. 2006. Disponível em: <http:// www.eco.unicamp.br/asp-scripts/boletim_ceri/boletim/boletim8/07_GOTTSCHALK.pdf > .

ONO, Fábio Hideki. O Acordo de Basiléia, a Adequação de Capital e a Implementação no Sistema Bancário Brasileiro. 2002. 117 f. (Monografia) - Instituto de Economia, Universidade Estadual de Campinas, Campinas, 2002.

SIEGEL, Sidney. Estatística Não-Paramétrica: Para as ciências do comportamento. São Paulo: McGraw-Hill do Brasil, 1975.

SILVA, Denis Blum Ratis e. O impacto de requerimentos de capital na oferta de crédito bancário no Brasil. 2005. 74 f. Dissertação (Mestrado em Economia) - Programa de PósGraduação em Economia, Universidade de São Paulo, São Paulo, 2005.

TRIOLA, Mario F. Introdução à Estatística. LTC, 7. ed. 1999. 